\title{
The role of community health workers in addressing the global burden of ear disease and hearing loss: a systematic scoping review of the literature
}

\author{
James O'Donovan, ${ }^{1,2}$ Misha Verkerk, ${ }^{3}$ Niall Winters, ${ }^{\oplus 1}$ Shelly Chadha, ${ }^{4}$ \\ Mahmood F Bhutta ${ }^{5}$
}

To cite: O'Donovan J, Verkerk M, Winters N, et al. The role of community health workers in addressing the global burden of ear disease and hearing loss: a systematic scoping review of the literature. BMJ Glob Health 2019;4:e001141. doi:10.1136/ bmjgh-2018-001141

Handling editor Seye Abimbola

- Additional material is published online only. To view please visit the journal online (http://dx.doi.org/10.1136/ bmjgh-2018-001141).

Received 27 August 2018 Revised 18 January 2019 Accepted 25 January 2019

Check for updates

(c) Author(s) (or their employer(s)) 2019. Re-use permitted under CC BY. Published by BMJ.

${ }^{1}$ Department of Education, University of Oxford, Oxford, UK ${ }^{2}$ Division of Research and Health Equity, Omni Med, Mukono, Uganda

${ }^{3}$ Department of Otolaryngology, King's College Hospital NHS Foundation Trust, London, UK ${ }^{4}$ WHO Programme for Prevention of Deafness and Hearing Loss, World Health Organization, Geneva, Switzerland

${ }^{5}$ Department of ENT, Brighton and Sussex University Hospitals NHS Trust, Brighton, UK

Correspondence to Dr James 0'Donovan; james.odonovan@seh.ox.ac.uk

\section{ABSTRACT}

Introduction Community health workers (CHWs) have the potential to improve access to ear and hearing services for people across low-income or middle-income countries, remote, underserved, or resource-poor areas of the world. We performed a systematic scoping review to identify evidence on how CHWs are currently deployed in the prevention, screening, diagnosis, treatment and management of ear disease and hearing loss; methods to train and support CHWs in this context; and costeffectiveness of CHWs.

Methods We performed a systematic search of the literature from September 1978 to 18 March 2018 from 11 major databases and the grey literature.

Results We identified 38 original studies that met the inclusion criteria, taking place across South Asia $(n=13)$, Oceania $(n=7)$, North America $(n=7)$, South America $(n=6)$ and Africa $(n=5) .23$ studies showed CHWs can increase community participation in screening. They can conduct screening using whispered voice tests, noisemakers for neonatal screening, automated audiological tests and otoscopy. Eight studies focused specifically on the evaluation of programmes to train $\mathrm{CHWs}$, and three provided a general programme description. Three studies documented a role of CHWs in the treatment of ear disease or hearing loss, such as performing ear washouts, instillation of topical antibiotics or fitting of hearing aids. Only one study provided an indepth cost-utility analysis regarding the use of $\mathrm{CHWs}$ to conduct hearing screening, and no studies commented on the role of CHWs in the prevention of hearing loss.

Conclusion CHWs have been employed in diverse ways to address the global burden of ear disease and hearing loss. Future research needs to explore the role of $\mathrm{CHWs}$ in preventative strategies, identify optimum methods to train and support CHWs, and explore their cost-effectiveness.

\section{INTRODUCTION}

Hearing loss has an enormous global economic impact, estimated at 750 billion international dollars annually, with $63 \%-73 \%$ of these costs incurred in low-income or middle-income countries (LMICs). ${ }^{1}$ Yet, given

\section{Key questions}

What is already known?

- The global burden of disabling hearing loss is unequally distributed, with $80 \%$ of those affected living in low-income or middle-income countries (LMICS).

- To address the shortage of specialist ear care professionals in LMICs and resource-poor areas of the world, community health workers (CHWs) have been proposed as one strategy to fill the gap in human resources for health.

\section{What are the new findings?}

- This systematic scoping review is the first to try and identify a role of CHWs to improve access to ear and hearing services for people across LMICs, remote, underserved or resource-poor areas of the world.

- We identified 38 original studies that met the inclusion criteria.

What do the new findings imply?

- CHWs could potentially play an important role in improving access to ear and hearing services, including in screening, raising community awareness and delivery of basic treatment.

- Future research needs to explore the role of CHWs in preventative strategies, identify optimum methods to train and support CHWs, and explore their cost-effectiveness.

the multitude of other competing issues, hearing loss is rarely acknowledged,,$^{2}{ }^{3}$ let alone prioritised in resource-limited settings, and as such has been termed 'the invisible disability'. ${ }^{4}$ At an individual level, hearing loss in childhood can cause oral language and communication impairment, leading to adverse effects in educational attainment and behaviour. ${ }^{56}$ In adults or the elderly, hearing loss is associated with depression, dementia and social isolation. ${ }^{7-9}$

Importantly, the global burden of disabling hearing loss is unequally distributed.$^{10}$ Of the 
$6.1 \%$ of the global population affected, ${ }^{11}$ the prevalence of child and adult hearing impairment is substantially higher in LMICs, most of which lack the human or other resources to prevent, diagnose or treat such disease. ${ }^{12} 13$ A WHO report from 2013 revealed that $64 \%$ of participating countries from the African region had fewer than one ear, nose and throat (ENT) surgical specialist available per million people, compared with 12 in some high-income countries. ${ }^{14}$ Similarly, $88 \%$ of high-income countries reported availability of more than one audiologist per million population, compared with only $5 \%$ in low-income countries. ${ }^{14}$ Furthermore, it is important to note that even within countries, ENT surgeons and audiologists are unequally distributed. ${ }^{15}$ Training highly skilled health workers, such as audiologists or surgeons, is expensive, time-consuming, and reinforces a hospital-based model of care that may fail to reach disadvantaged or remote populations. One proposed solution for the recognition and treatment of ear disease and hearing loss is task shifting to cadres of health workers with less specialised training, such as community health workers (CHWs). ${ }^{3} 1617$

In the broadest sense, CHW is an umbrella term for laypeople working within their own community in a health promotion, prevention and delivery role $^{18}$; however, the nomenclature used to describe CHWs is wide-ranging, and their exact roles, responsibilities, recruitment, remuneration and training vary from country to country. ${ }^{19}$ CHWs have been successful in providing care for infectious diseases, and for maternal and child health, ${ }^{20}$ and this approach could be emulated for ear and hearing health. ${ }^{1}$ This concept is not new; basic ear care workers have been active in rural indigenous communities in Australia and Canada since the 1980s. ${ }^{21} 22$

In this scoping review we mapped the existing literature for evidence on the role CHWs may play in addressing the global burden of ear disease and hearing loss. Specifically we sought evidence to evaluate four predetermined questions:

1. How are CHWs currently deployed in the prevention, screening and diagnosis of ear disease and hearing loss?
2. How are CHWs deployed in the treatment and management of ear disease and hearing loss?

3. What methods exist to train and support CHWs in ear disease and hearing loss? What are the contents, duration and outcomes of such training?

4. What is the cost-effectiveness of using CHWs in ear disease and hearing loss?

\section{METHODS}

\section{Nature of review}

We conducted a scoping review on the role of CHWs in ear disease and hearing loss to identify existing evidence and gaps in the literature. A scoping review is defined as that which addresses an exploratory research question through mapping key concepts, types of evidence and gaps in research by systematically searching, selecting and synthesising knowledge in a field. ${ }^{23}$ Hence, scoping reviews provide a broad overview and organisation of existing knowledge, as opposed to the narrow synthesis of a predefined research question typical of a systematic review. ${ }^{24-26}$ They also place less emphasis on the critical appraisal of the included evidence compared with a traditional systematic review. ${ }^{26}$

A scoping literature review was chosen for this study since it enabled us to review a broad body of literature and map the current ways CHWs are trained and deployed to deal with ear disease and hearing loss across a variety of different geographical contexts.

\section{Search strategy and study selection}

A search of the Cochrane Library, the Campbell Collaboration, the International Prospective Register of Systematic Reviews (PROSPERO) and grey literature identified no existing or scheduled reviews on this topic.

We designed an exhaustive and sensitive search strategy through developing terms for 'community health workers', 'hearing loss' and 'ear disease'. There were combined using the AND operator in a master search string (see table 1, online supplementary material). Where appropriate, Medical Subject Headings (MeSH) terms were exploded to relevant subheadings,

Table 1 Roles of CHWs in ear and hearing disease that have been reported in the literature or have potential (as indicated by an asterisk)

\begin{tabular}{|c|c|c|c|}
\hline Training level & Basic & Intermediate & Advanced \\
\hline $\begin{array}{l}\text { Screening and } \\
\text { diagnosis. }\end{array}$ & $\begin{array}{l}\text { Encouraging } \\
\text { community } \\
\text { participation. }\end{array}$ & $\begin{array}{l}\text { Taking a clinical history.* } \\
\text { Clinical tests of hearing (whispered voice test, } \\
\text { noisemakers for neonatal screening). } \\
\text { Automated audiometry (eg, PTA, OAE, ABR). } \\
\text { Otoscopy (store and send). } \\
\text { Otoscopy (diagnostic).* }\end{array}$ & $\begin{array}{l}\text { Diagnostic audiometry } \\
\text { (eg, PTA, paediatric } \\
\text { audiological tests). }\end{array}$ \\
\hline Treatment. & $\begin{array}{l}\text { Raising awareness. } \\
\text { Preventative } \\
\text { measures. }{ }^{*}\end{array}$ & $\begin{array}{l}\text { Ear washout. } \\
\text { Antibiotic therapy. } \\
\text { Dry mopping of the ear.* }\end{array}$ & $\begin{array}{l}\text { Fitting and } \\
\text { maintenance of } \\
\text { hearing aids. }\end{array}$ \\
\hline
\end{tabular}

ABR, auditory brainstem response; CHW, community health worker; OAE, otoacoustic emissions; PTA, pure tone audiometry. 
and synonyms searched for each key term, along with wildcards and truncation for free-text words.

In this study (and consistent with agreed definitions), ${ }^{27}$ we defined CHWs as health workers who are members of the communities where they work, but without formal professional or paraprofessional certificated tertiary education. They should work in the community (rather than a health facility), belong to the formal health system (managed by the government or non-governmental organisation) and perform tasks related to healthcare delivery. ${ }^{19} 2$

We searched the following databases for studies published between 12 September 1978 (the date of the Alma Ata Declaration, which declared CHWs as central to primary healthcare ${ }^{29}$ and 18 March 2018: Medline; Embase, Allied and Complementary Medicine Database and Global Health via Ovid; Cumulative Index to Nursing and Allied Health Literature via Ebsco; PsycINFO; Web of Science; Scopus; Applied Social Sciences Index and Abstracts via ProQuest; British Education Index; and Education Resources Information Center (the full search strategy for each database is listed in online supplementary table 1). We included additional non-peer-reviewed literature identified through the e-theses online service (ETHoS), Google Scholar, and websites of research institutions, charities, relevant government departments and international agencies involved in ear and hearing care. We also conducted a manual search of grey literature databases (see online supplementary table 2). Finally, we searched the reference lists of all relevant papers identified, using snowball sampling. No restrictions were placed on language.

Regarding inclusion and exclusion criteria, studies were included if:

1. The primary participants of the study were CHWs (as per the definition outlined above).

2. The primary aim of the study was to describe or evaluate the role of CHWs in the prevention, screening, diagnosis, treatment and/or management of ear disease and/or hearing loss.

Studies were excluded if:

1. The primary focus of the study was on health workers other than CHWs (eg, doctors, medical students, nurses or allied healthcare professionals, such as midwives).

2. The study did not contain sufficient information to extract meaningful information regarding the role of CHWs in ear disease and/or hearing loss. For example, studies which focused on describing the roles of CHWs in managing a broad range of diseases but only mentioned their role in ear disease or hearing loss in passing were excluded.

3. The study was not a primary research or descriptive study relevant to addressing the four predetermined research questions. We excluded letters, commentaries, opinion pieces, study protocols, policy briefings, training needs assessments and conference abstracts.
Identified papers were exported into EndNote V.7.1 and duplicates were removed. Titles and abstracts were screened by two authors (JOD and MV), and the full text of potentially relevant papers retrieved and reviewed. Data from the full text were extracted and entered into a Microsoft Excel data charting form. Each reviewer had a copy of the inclusion and exclusion criteria to hand when completing this process. Where the reviewer felt the study should be excluded, they noted this in the data charting form and provided a reason for exclusion. Disagreement between reviewers was resolved via discussion and by referring to the inclusion and exclusion criteria. Where needed, we contacted the authors of individual studies for further information.

A review protocol was not published and the study was not registered with PROSPERO, as these mechanisms are not applied to scoping reviews. ${ }^{23} 24$

\section{Data extraction}

JOD extracted and tabulated relevant data from each included study, including the study author, title, date of publication, country and region in which the study took place, CHW name and cadre description, the number of CHWs involved, the primary aims and outcomes of the programme, whether or not government or CHWs were involved in programme planning or design, financial data, details of training, the focus theme of the paper, and whether eHealth or telemedicine was used. MV checked data extraction for accuracy. At all stages, disagreements between the review authors were resolved via discussion.

\section{RESULTS \\ Search results}

The initial search yielded 674 articles, which reduced to 420 after removal of duplicates (see online supplementary table 3 ). After screening of abstracts, 356 studies were excluded and after full-text review a further 30, leaving 38 studies that met the inclusion criteria. ${ }^{21}{ }^{22}{ }^{30-65}$ Further details are in the Preferred Reporting Items for Systematic Reviews and Meta-Analyses flow chart (figure 1).

\section{Characteristics of included studies}

Across the studies 15 different terms were used to define CHWs, with significant variations in cadre roles, responsibilities and status. Some CHWs, such as the Siutilirijiit and Aaniasiurtiapiit in Canada, were full-time workers focused solely on the provision of ear care. ${ }^{35}{ }^{37}$ In other studies CHWs had additional responsibilities, such as providing maternal and child healthcare. ${ }^{5257}$

The majority of studies have been published in the past decade (since 2008, $\mathrm{n}=30$ ), with no relevant studies published before 1980. Studies took place in South Asia $(\mathrm{n}=13),{ }^{30} \quad 36 \quad 43-4548$ 55-59 $61 \quad 65$ Oceania $(\mathrm{n}=7),{ }^{21} 383941426263$ North America $(\mathrm{n}=7),{ }^{22} 353747495060$ South America $(\mathrm{n}=6)^{31-344064}$ or Africa $(\mathrm{n}=5) .{ }^{4651-54}$

Full details of CHW cadre descriptions and study characteristics can be found in online supplementary table 4 . 


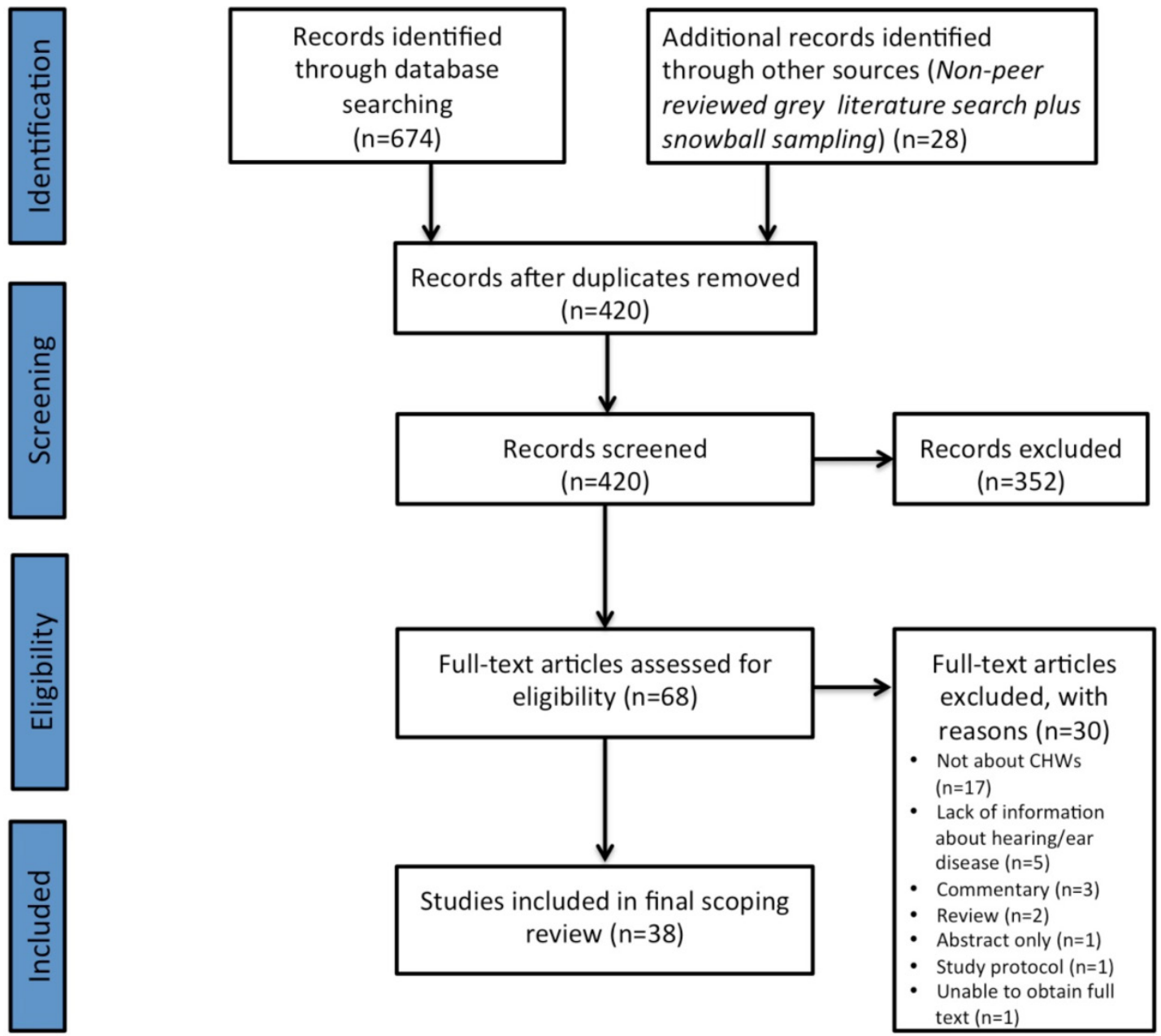

Figure 1 PRISMA diagram. The PRISMA diagram details our search and selection process applied during the scoping review. CHWs, community health workers; PRISMA, Preferred Reporting Items for Systematic Reviews and Meta-Analyses.

\section{Prevention, screening and diagnosis of ear disease and hearing loss by CHWs}

We identified 23 studies which primarily focused on the role of CHWs in screening for ear disease and hearing loss. ${ }^{21} 303136424345-47$ 49-51 53-56 $585961-6466$ There were no studies on the role of CHWs in disease prevention.

In the most basic terms, CHWs have been used to facilitate community attendance at hearing screening camps run by experts. ${ }^{4461}$ In India, Emerson $e t ~ a l^{44}$ reported that CHWs mobilised 2600 patients from the community to attend 20 hearing screening camps held in the Vellore District of Tamil Nadu between 2009 and 2011. In Nepal, Shrestha et $a l^{61}$ reported that using CHWs to mobilise rural community members resulted in a $20 \%$ increase in attendance at hearing camps over an 18 -month period. ${ }^{61}$

CHWs have also been evaluated for their own potential for undertaking screening, to identify either hearing loss $3031364346485053-565864$ or other ear disease. ${ }^{21} 38424445495961-63$

Alvarenga $e t a l^{31}$ used a locally devised questionnaire administered by 66 CHWs in Brazil to screen for childhood hearing loss. They screened 304 children; however, the sensitivity of the questionnaire was poor: only 1 of 69 children with conductive hearing loss and 4 of 6 with sensorineural hearing loss were identified (no data were provided on the severity of hearing loss identified). Wagner et $a l^{64}$ gave a similar questionnaire to a cadre of CHWs to screen for infant hearing loss in Brazil. This required monthly administration of the questionnaire for 6 months, and was only used with parents of infants who had already passed newborn hearing assessment. Only $15 \%(6 / 41)$ of CHWs completed the study, with attrition over the duration of the study. Many CHWs cited high existing workloads as the reason for non-completion, ${ }^{64}$ but additional factors may have been that the screened population was at low risk of disease, that the questionnaire itself had not been validated, and fatigue set in given the recommendation to administer the questionnaire every month to the same participants.

The whispered voice test is established as a valid clinical screening test for hearing loss in adults and older children, but most studies have evaluated its administration by experts only. ${ }^{67}$ In a broad screen of disability in 150 frail and elderly adults, Jotheeswaran $e t a l^{48}$ evaluated the whisper test administered by CHWs in India, compared with that by physicians with over 10 years of primary care experience. ${ }^{48}$ Of those screened, 104 failed assessment by CHWs, with $71 \%$ concordance with the physicians. It is 
important to note that the assessment by both the CHWs and physicians did not include audiometry, and so the true validity of this approach remains unclear, nor is it known if this approach may be valid in other populations.

Yousuf Hussein $e t a l^{46}$ conducted a study in South Africa exploring CHWs' use of the automated pure tone audiometry (PTA) screening mobile phone application hearScreen which has previously been validated for accuracy. ${ }^{68}$ In this study $12 \%$ of adults and $6.5 \%$ of children from the community were referred for further assessment, and CHWs reported the method to be acceptable and time-efficient. ${ }^{46}$ PTA conducted by CHWs was mentioned in several studies; however, details of how the CHW were trained to conduct complex audiological testing were not provided. ${ }^{42}{ }^{62}$ Elliott et at $t^{42}$ reported that 157 of $442(35 \%)$ Australian Aboriginal patients screened by PTA were referred to a specialist, but did not report the validity of the PTA performed by CHWs. No other study reported on the validity of CHW-conducted PTA.

CHWs have also been trained in play audiometry. Berg et $a l^{36}$ described a 2-week training course for CHWs in Bangladesh,${ }^{36}$ followed by screening with play audiometry of 4003 children aged 2-9 years old. However, they found that $66 \%$ of the younger children (aged 2-5) were untestable, which perhaps reflects the complexity and special skillset required to test hearing in young children. No study reported on the validity of CHW-conducted play audiometry.

For neonatal hearing loss, Ramesh et a $l^{\tilde{5}}$ described screening by CHWs in rural India using a locally made noisemaker consisting of a wooden cylinder filled with plastic and metal beads. Of the 425 neonates screened, 20 were purposively selected with significant hearing loss (requiring aiding). When performed at a 70-80 dB(A) stimulus, this method was found to have $100 \%$ sensitivity and $95 \%-97 \%$ specificity, compared with the gold-standard otoacoustic emissions (OAE) and auditory brainstem response (ABR) testing by an audiologist.

Automated neonatal screening tests can also be performed by CHWs. Akilan ${ }^{30}$ demonstrated that CHWs in India could undertake OAE testing following a 2-week training programme, but noted that the time taken to conduct screening was between 30 and $120 \mathrm{~min}$, which is much longer than the 3-8 min to perform OAE testing reported in high-resource settings ${ }^{69}{ }^{70}$ Background noise was also noted to be an issue for screening in the community. ${ }^{30}$ Similarly, Olusanya $e t a \tilde{l}^{4}$ reported an $88 \%$ success rate of CHWs in Nigeria performing automated OAEs and ABR testing in clinic. But here they noted a significant loss to follow-up in those testing positive, which they surmised to be due to sociocultural factors, including stigma associated with hearing loss.

Several studies have shown that CHWs are able to capture images using otoendoscopy to forward for expert assessment. ${ }^{3841424549}$ Kokesh et at $t^{49}$ described capture of postoperative images following tympanostomy tube placement by CHWs in rural Alaska. Remote evaluation of these images by an ENT specialist deemed that $79 \%$ of the images were 'adequate' for diagnosis. Similarly, Elliot et al found that $90 \%$ of otoendoscopic image captures by CHWs screening remote indigenous children in Australia (aged 0-16) were deemed 'excellent' by a remote ENT specialist. ${ }^{42}$

\section{Treatment and management of ear disease and hearing loss by CHWs}

Three studies described a role of CHWs in the treatment of ear disease and hearing loss. ${ }^{22} 3843$ In a clinical trial, Couzos $e t a l^{8}$ described twice-daily administration of ear washouts and ototopical antibiotic therapy by CHWs for 9-10 days to Australian Aboriginal children with chronic suppurative otitis media. Ear washout and ciprofloxacin eardrops resulted in a $76 \%$ cure rate for resolution of otorrhoea at 2 weeks, which compares with success rates for similar treatment regimens in a hospital setting. ${ }^{71}$ Despite such an intensive treatment regimen, over $76 \%$ of children (111/147) completed the full treatment course, which may reflect the engagement of the community in this trial. ${ }^{38}$

Emerson $e t a t^{43}$ reported that after 6 weeks of targeted training, CHWs in India were able to fit and programme hearing aids, as well as provide counselling to community members who needed to use them. This resulted in a very high acceptance rate of $98 \%$ and reduced feelings of shyness among community members wearing a hearing aid. ${ }^{43}$ Specifically trained CHWs have also fitted hearing aids in remote regions of Canada. ${ }^{22}$

\section{Methods for training and support of CHWs}

In eight studies, the primary focus was in evaluating the delivery of CHW training programmes. ${ }^{32-34} 4041526065$ There was a great deal of heterogeneity between studies regarding content, duration and method of delivery, making direct comparison difficult.

Some training programmes, such as that by Eikelboom et $a l^{41}$, provided indepth coverage of topics including a theoretical background on the anatomy and physiology of the ear, and an outline of the causes, prevention and treatment of common ear diseases. Other training programmes were focused on one key area, such as diagnostic otoscopy skills. ${ }^{65}$ Five studies referred to the use of the WHO Primary Ear Care Training Manuals as the educational resource, ${ }^{32-34} 4052$ whereas the remainder did not detail the training content or how it was developed.

Training was delivered mainly through inperson workshops or classes, although four studies exploited digital technologies. ${ }^{33} 344041$ For example, Araújo $e t a l^{34}$ used a computer-based 'Cybertutor' platform to train 24 CHWs in Brazil.

Training duration was not commonly reported, but where it was, it was often brief, ranging between 3 and 8 hours, in a one-off training session. ${ }^{33} 52$ Interestingly, Araújo $e t a l^{34}$ noted that after initial training, assessment scores of CHWs improved, but were significantly worse 15 months later. No studies reported ongoing training of CHWs. 
The effectiveness of training was commonly evaluated through the use of pretraining and post-training knowledge assessments ${ }^{32-34}$; however, some studies also evaluated training effectiveness through change in practice. For example, in the study by Mulwafu et a $a \tilde{l}^{2}$ in Malawi, health surveillance assistants were asked to identify patients at risk of ear disease and hearing loss to be screened in the community. Of the 1739 patients identified in the community as having potential ear and hearing disorders, they were successfully able to mobilise 860 patients to attend screening camps, of whom 400 had hearing loss. Sanchéz et $a b^{60}$ chose not to evaluate training effectiveness through pretraining and post-training knowledge assessments, and rather focused their evaluation on qualitative assessments of improvements in confidence and the perceived ability of CHWs to provide family support and make referrals for specialist input.

\section{Cost-effectiveness of CHWs in delivering ear and hearing care}

There was a paucity of studies discussing the financial implications of training and using CHWs to provide ear and hearing care. Only Ramkumar $e t a \tilde{l}^{7}$ provided sufficient analysis to conclude that using CHWs and tele-ABR to conduct community screening for childhood hearing loss was cost-effective. They compared conducting telediagnostic ABR in a mobile van using satellite connectivity with a local centre using broadband internet in a rural location. According to the authors, the difference in cost between using satellite connectivity in a mobile van versus broadband internet was ' $\$ 1.14$ per child screened, $\$ 80$ per child followed-up and $\$ 304$ per child identified'. ${ }^{57}$

Several other studies provided basic costs of interventions or programmes, but no cost-benefit or cost-effectiveness analyses. For example, Yousuf Hussein et $a l^{46}$ discussed the costs of the mobile-based hearScreen application, yet failed to provide details on the costs of ongoing technical support and long-term maintenance. Similarly, Olusanya et a $\tilde{l}^{\tilde{3}}$ estimated the cost of infant screening in Nigeria was 'less than \$8 USD' per child, but did not provide details on how this was calculated.

Akilan et $a \vec{l}^{30}$, in their evaluation of neonatal hearing screen in impoverished communities in South India, found that 73 of $82(89 \%)$ mothers were willing to pay something for their children to be screened, but only 20 of $82(24 \%)$ could afford the full costs.

Full details of studies are in online supplementary table 4.

\section{DISCUSSION}

This review has identified a number of studies on the use of CHWs in screening, diagnosis and treatment of ear and hearing disease; however, few demonstrated robust outcomes or long-term results. Nevertheless, these studies show that CHWs can be used for delivery of such care, and based on both the evidence presented here and evidence from other contexts (detailed below), we propose a model for incorporation of CHWs into programmes for tackling the burden of ear and hearing disease (see table 1 ).

At a basic level, the evidence suggests that CHWs can successfully raise community awareness of ear disease and hearing loss, and promote participation in screening programmes. It is likely this requires low-intensity training of CHWs, and that such CHWs could also be deployed to promote preventative measures, such as encouraging vaccination or smoking cessation to reduce risk of otitis media or limitation of noise exposure to prevent noise-induced hearing loss. CHWs have been successfully used in tobacco control measures and vaccination programmes in other contexts. ${ }^{72} 73$

After an intermediate level of training, CHWs could perform clinical examination to screen for disease, including use of otoscopy, whispered voice tests for evaluating hearing in older children and adults, and noisemakers for screening for hearing loss in babies. They could also perform automated tests of hearing, including PTA, OAE and ABR. No studies have evaluated the ability of CHWs to take a clinical history of ear and hearing disease, nor tools to help enable that.

In terms of treatment, Couzos $e t a l^{88}$ used CHWs to perform ear washouts and instil antibiotic drops; however, we identified a paucity of studies assessing the role of CHWs in administering treatment. Given appropriate ethical clearance and safety considerations, this is an avenue that should be evaluated in the future. Given the severe shortage of trained ear specialists in LMIC settings, exploring ways to train CHWs to provide simple, low-risk treatment options (such as dry mopping or administering eardrops) may help free up time for more complex disorders to be managed by specialist ear care professionals.

Our review has also identified reports of CHWs successfully performing PTA and fitting and maintenance of hearing aids. This is presumably after a prolonged period of expert tuition; however, exact training details were not provided. It is noteworthy that Berg $e t a \vec{l}^{36}$ reported little success with paediatric audiological testing after training CHWs for 2 weeks, and perhaps a prolonged period of training could have led to greater success here. However, due to the lack of details regarding specific training strategies and outcomes, it is difficult to pinpoint areas for improvement.

\section{Enabling CHWs: barriers and opportunities}

In reality, the role that individual cohorts of CHWs can play in ear and hearing disease will be contingent on many factors. Although there is variation in training and capacity of CHWs across countries, there is no one-sizefits-all approach for CHW programmes. Any programme should be adapted to suit the needs of local contexts. Some countries or regions do not have CHW availability, and where they do may not recognise ear and hearing disease as a priority. ${ }^{74}$ Where CHWs exist, they may have 
limited time to devote to ear and hearing disease due to competing priorities, whereas others may have more time or be dedicated ear care workers. Some will have little background knowledge or training in healthcare, others may be well versed in such matters and so more readily able to take on roles. Some may have access only to online or written training resources, others to expert face-to-face tuition. Some will have access to specialist equipment, others will not. This has resulted in a fragmented landscape of CHW programmes, with varying levels of resources and support. ${ }^{75}$

It is also important to recognise barriers to community participation. For example Gupta et $a t^{5}$ noted that many community members in northern India did not understand the need for hearing screening and several refused participation due to fear. In Nigeria, Olusanya et $a \tilde{l}^{4}$ noted delay in follow-up of infants identified as at risk of hearing loss, perhaps because community members did not view such disease as life-threatening or urgent, or because of associated stigma. In impoverished regions of eastern India, Ramkumar et $a \tilde{l}^{7}$ reported that many at-risk children were not brought for follow-up testing of hearing due to prohibitive costs of travel and potential loss of earnings. Mulwafu et $a \Gamma^{52}$ found that almost $50 \%$ of villagers in Malawi identified as having potential ear and hearing disorders did not attend a hearing screening camp because it clashed with a fertiliser handout. Taking a human-centred design approach towards community-based hearing health programmes may therefore help to reduce such challenges in the future. ${ }^{76}$ Giacomin $^{77}$ defines human-centred design as the use of techniques 'which communicate, interact, empathize and stimulate the people involved, obtaining an understanding of their needs, desires and experiences which often transcends that which the people themselves actually realized'. Such approaches have been used successfully in other health conditions such as cancer, ${ }^{78} \mathrm{HIV}$ and tubercu$\operatorname{losis}^{79}$ to help improve patients' overall experience of care, tailor approaches in a contextually appropriate manner and improve the delivery of health services.

An additional barrier is the availability of incountry expert services. Screening programmes may be futile if treatment of disease is not available, ${ }^{80}$ and in most LMICs the availability of hearing aids, audiologists, ENT surgeons, or speech and language therapists is sparse or non-existent. ${ }^{74}$ It is important that the level of clinical care provided by CHWs is commensurate with their standard of training and skill. There should be robust systems for onward specialist referral in complex clinical cases. ${ }^{81}$ Clear information on the specific care provided by CHWs may help protect CHWs from unrealistic expectations within local communities. As highlighted by the WHO, ${ }^{18}$ CHWs cannot be seen as a panacea to solving the burden of global ear disease, and governments must continue to invest in audiology, speech and language, and ENT services, which need to be developed in parallel with the training of CHWs.
Recent thinking has shifted towards 'how CHWs can support health systems beyond vertical interventions'. ${ }^{82}$ CHWs should be seen as one piece of a complex puzzle, which requires investment at all levels from primary through to tertiary care. It also requires that CHWs are paid, receive ongoing training and are supported for long-term retention by the health systems within which they are located. ${ }^{82}$

\section{Review limitations}

It is important to note that CHWs work within complex health systems, which are significantly variable between individual countries. This means the generalisability of findings across studies to different contexts is difficult. There was a high concentration of studies in South America, Oceania and South Asia. We would encourage further studies across a wider variety of geographical locations.

Second, although we have tried to create a search strategy using as many possible relevant terms and using the most widely accepted definitions, there is no fixed definition of a CHW, and so some exclusions may be contested.

Finally, given the nature of scoping review, a critical appraisal of studies was not undertaken. This represents a limitation since we are unable to comment on the quality of the included studies.

\section{Future needs}

There are several opportunities to promote CHW participation in ear and hearing care.

The value of existing training resources is not known. The WHO Primary Ear Care Training Manuals were the single most commonly cited training material, although many studies did not provide details of resources used to train CHWs. Most studies used pretraining and posttraining multiple-choice questions as their outcome measure of learning. ${ }^{32} 334041$ There is a risk that such measures equate exposure to information as a proxy for education, ${ }^{83}$ rather than measures such as the ability of CHWs to diagnose and treat ear disease in a real-world environment. Future studies on training may benefit from participation of CHWs in the development of learning resources, evaluation of practical outcomes rather than knowledge-based outcomes, and evaluation of long-term rather than short-term educational outcomes. ${ }^{84}$ Digital or mobile technologies could enhance delivery of training and provision of ongoing expert support, ${ }^{83} 85$ which have shown promise in other areas of CHW training. ${ }^{86}$

Additional factors that may enable CHWs is the development of relevant low-cost technologies, including otoscopes, noisemakers, audiometers, hearing aids and training aids. The availability of tools for automated mobile phone-based hearing screening is a promising development. $^{46588788}$

Finally, more work is needed to explore the cost-effectiveness of CHWs in ear and hearing care, factoring 
costs of recruitment, training and ongoing support, and models for reimbursement. ${ }^{89}$

\section{CONCLUSION}

CHWs have demonstrated the potential to address the gap in ear and hearing services for the screening and treatment of disease. This approach offers promise both in terms of strengthening local and national health systems and carries positive implications for individuals and society more broadly. However much of the existing research has not explored their role in preventative strategies, optimum methods to train and provide ongoing support for CHWs, nor identified if such models are sustainable and cost-effective. Future studies should address these knowledge gaps with high-quality evidence, as well as explore additional barriers to CHW participation, including the provision of affordable technologies for diagnosis and treatment, and community engagement.

Acknowledgements We thank Catherine Scutt, Bodleian Education Librarian at the University of Oxford, for helping to refine the database search strategy.

Contributors Activities undertaken by the authors were as follows: establishment of research question(s) and development of search strategy: JOD, NW, MFB; background framing: JOD, MFB, NW; database search and record screening: JOD and MV; extraction of primary studies from the included reviews: JOD and MV; discussion and conclusions: JOD, NW, MV, SC, MFB. All authors agree to take public responsibility for the paper's content and have approved the final paper prior to submission.

Funding JOD is a DPhil candidate at the University of Oxford supported by a grant from the Economic and Social Research Council (ES/P000649/1) and The British Medical Association Charitable Arm.

Competing interests None declared.

Patient consent for publication Not required.

Ethics approval Since this was a systematic scoping literature review of existing data, ethical approval was not sought.

Provenance and peer review Not commissioned; externally peer reviewed.

Data sharing statement All data are contained within the main body of the text and in the online supplementary material.

Open access This is an open access article distributed in accordance with the Creative Commons Attribution 4.0 Unported (CC BY 4.0) license, which permits others to copy, redistribute, remix, transform and build upon this work for any purpose, provided the original work is properly cited, a link to the licence is given, and indication of whether changes were made. See: https://creativecommons.org/ licenses/by/4.0/.

\section{REFERENCES}

1. The World Health Organization Department for Management of NCDs Disability Violence and Injury Prevention. Action for hearing loss: making a sound investment, 2017. Available: http://www.who. int/pbd/deafness/world-hearing-day/WHD2017Brochure.pdf

2. Boutayeb A. The double burden of communicable and noncommunicable diseases in developing countries. Trans $R$ Soc Trop Med Hyg 2006;100:191-9.

3. Chadha S, Cieza A, Krug E. Global hearing health: future directions. Bull World Health Organ 2018;96.

4. Shohet JA, Bent T. Hearing loss: the invisible disability. Postgrad Med 1998;104:81-90.

5. Bennett KE, Haggard MP, Silva PA, et al. Behaviour and developmental effects of otitis media with effusion into the teens. Arch Dis Child 2001;85:91-5.

6. Stevenson J, McCann D, Watkin P, et al. The relationship between language development and behaviour problems in children with hearing loss. J Child Psychol Psychiatry 2010;51:77-83.
7. Solheim J, Kværner KJ, Falkenberg E-S. Daily life consequences of hearing loss in the elderly. Disabil Rehabil 2011;33:2179-85.

8. The Lancet. Hearing loss: time for sound action. Lancet 2017;390.

9. Cherko M, Hickson L, Bhutta M. Auditory deprivation and health in the elderly. Maturitas 2016;88:52-7.

10. Wilson BS, Tucci DL, Merson MH, et al. Global hearing health care: new findings and perspectives. Lancet 2017;390:2503-15.

11. The World Health Organization. Prevention of blindness and deafness, 2018. Available: https://www.who.int/pbd/deafness/ estimates/en/

12. Mulwafu W, Kuper H, Ensink RJH. Prevalence and causes of hearing impairment in Africa. Trop Med Int Health 2016;21:158-65.

13. Stevens G, Flaxman S, Brunskill E, et al. Global and regional hearing impairment prevalence: an analysis of 42 studies in 29 countries. Eur $J$ Public Health 2013;23:146-52.

14. The World Health Organization. Multi-country assessment of nationa capacity to provide hearing care, 2013. Available: http://www.who. int/pbd/publications/WHOReportHearingCare_Englishweb.pdf

15. Mulwafu W, Ensink R, Kuper H, et al. Survey of ENT services in subSaharan Africa: little progress between 2009 and 2015. Glob Health Action 2017;10.

16. Crisp N, Chen L. Global supply of health professionals. N Engl J Med 2014;370:950-7.

17. Frenk J, Chen L, Bhutta ZA, et al. Health professionals for a new century: transforming education to strengthen health systems in an interdependent world. Lancet 2010;376:1923-58.

18. The World Health Organization. Community health workers: what do we know about them? 2007. Available: http://www.who.int/hrh/ documents/community_health_workers_brief.pdf

19. Olaniran A, Smith $H$, Unkels $R$, et al. Who is a community health worker? - a systematic review of definitions. Glob Health Action $2017 ; 10$.

20. Ballard M, Montgomery P. Systematic review of interventions for improving the performance of community health workers in lowincome and middle-income countries. BMJ Open 2017;7:e014216.

21. Peever MV, Ward JA. Successful assault on ear disease: intensive daily treatment by nurses and health workers. Med J Aust 1980;1(1 Suppl):1-4.

22. Williams DM. Basic audiological and related services in the North -the role of a native technician. J Otolaryngol 1980;9:517-23.

23. Colquhoun $\mathrm{HL}$, Levac $\mathrm{D}, \mathrm{O}^{\prime}$ Brien $\mathrm{KK}$, et al. Scoping reviews: time for clarity in definition, methods, and reporting. J Clin Epidemiol 2014;67:1291-4.

24. Arksey H, O'Malley L. Scoping studies: towards a methodological framework. Int J Soc Res Methodol 2005;8:19-32.

25. Miake-Lye IM, Hempel S, Shanman R, et al. What is an evidence MAP? A systematic review of published evidence maps and their definitions, methods, and products. Syst Rev 2016;5.

26. Haby MM, Chapman E, Clark R, et al. What are the best methodologies for rapid reviews of the research evidence for evidence-informed decision making in health policy and practice: a rapid review. Health Res Policy Syst 2016;14.

27. The World Health Organization. Strengthening the performance of community health workers in primary health care. Report of a WHO Study Group. Who technical report series, no 780. who technical report series, No. 780. Geneva: World Health Organization, 1989.

28. Lewin SA, Dick J, Pond P, et al. Lay health workers in primary and community health care. Cochrane Database Syst Rev 2005;1.

29. The World Health Organization. Community health workers: what do we know about them? The state of the evidence on programmes, activities, costs and impact on health outcomes of using community health workers. Geneva: The World Health Organization, 2007.

30. Akilan R, Vidya R, Roopa N. Perception of 'mothers of beneficiaries' regarding a rural community based hearing screening service. Int $J$ Pediatr Otorhinolaryngol 2014;78:2083-8.

31. Alvarenga KdeF, Araújo ES, Melo TMde, et al. Questionnaire for monitoring auditory and language development in the first year. Codas 2013;25:16-21.

32. Alvarenga KF, Bevilacqua MC, Martinez MANS, et al. Training proposal for community health agents in hearing health. Pro Fono 2008;20:171-8

33. Araújo ES, de Freitas Alvarenga K, Urnau D, et al. Community health worker training for infant hearing health: effectiveness of distance learning. Int J Audiol 2013;52:636-41.

34. Araújo ES, Jacob-Corteletti L, Abramides D, et al. Community health workers training on infant hearing health: information retention. Revista CEFAC 2015;17:445-53.

35. Ayukawa H, Roy AM. Being outside of the box: audiology in northern Québec. Can J Speech Lang Pathol Audiol 2014;38:218-23. 
36. Berg AL, Papri H, Ferdous S, et al. Screening methods for childhood hearing impairment in rural Bangladesh. Int $\mathrm{J}$ Pediatr Otorhinolaryngol 2006;70:107-14.

37. Billard I. The hearing and otitis program: a model of community based ear and hearing care services for Inuit of Nunavik. Can $J$ Speech Lang Pathol Audiol 2014;38:206-17.

38. Couzos S, Lea T, Mueller R, et al. Effectiveness of ototopical antibiotics for chronic suppurative otitis media in Aboriginal children: a community-based, multicentre, double-blind randomised controlled trial. Med J Aust 2003;179:185-90.

39. Couzos S, Lea T, Murray R, et al. 'We are not just participants--we are in charge': the NACCHO ear trial and the process for Aboriginal community-controlled health research. Ethn Health 2005;10:91-111.

40. Melo TMde, Alvarenga KdeF, Blasca WQ, et al. Community health agents training on hearing health: effectiveness of video conference. Pro Fono 2010;22:139-44.

41. Eikelboom RH, Weber S, Atlas MD, et al. A tele-otology course for primary care providers. J Telemed Telecare 2003;9(Suppl 2):19-22.

42. Elliott G, Smith AC, Bensink ME, et al. The feasibility of a community-based mobile telehealth screening service for Aboriginal and Torres Strait Islander children in Australia. Telemedicine Journal and E-Health 2010;16:250-6.

43. Emerson LP, Job A, Abraham V. Pilot study to evaluate hearing aid service delivery model and measure benefit using self-report outcome measures using community hearing workers in a developing country. ISRN Otolaryngol 2013;2013:1-6.

44. Emerson LP, Job A, Abraham V. A model for provision of ENT health care service at primary and secondary Hospital level in a developing country. Biomed Res Int 2013;2013:1-5.

45. Gupta N, Chawla N, Gupta D, et al. Community triage of Otology patients using a store-and-forward telemedicine device: a feasibility study. Ear Nose Throat J 2017;96:246-9.

46. Yousuf Hussein S, Wet Swanepoel D, Biagio de Jager L, et al. Smartphone hearing screening in mHealth assisted communitybased primary care. $J$ Telemed Telecare 2016;22:405-12.

47. Ingram M, Marrone N, Sanchez DT, et al. Addressing hearing health care disparities among older adults in a US-Mexico border community. Front Public Health 2016;4:169-69.

48. Jotheeswaran AT, Dias A, Philp I, et al. Identifying common impairments in frail and dependent older people: validation of the cope assessment for non-specialised health workers in low resource primary health care settings. BMC Geriatr 2015;15.

49. Kokesh J, Ferguson AS, Patricoski C, et al. Digital images for postsurgical follow-up of tympanostomy tubes in remote Alaska. Otolaryngol Head Neck Surg 2008;139:87-93.

50. Marrone N, Ingram M, Somoza M, et al. Interventional audiology to address hearing health care disparities: oyendo bien pilot study. Semin Hear 2017;38:198-211.

51. Mukara KB, Waiswa P, Lilford R, et al. Knowledge and care seeking practices for ear infections among parents of under five children in Kigali, Rwanda: a cross-sectional study. BMC Ear Nose Throat Disord 2017:17.

52. Mulwafu W, Kuper H, Viste A, et al. Feasibility and acceptability of training community health workers in ear and hearing care in Malawi: a cluster randomised controlled trial. BMJ Open 2017;7:e016457 -e57.

53. Olusanya BO, Wirz SL, Luxon LM. Community-based infant hearing screening for early detection of permanent hearing loss in Lagos, Nigeria: a cross-sectional study. Bull World Health Organ 2008;86:956-63.

54. Olusanya BO, Akinyemi OO. Community-based infant hearing screening in a developing country: parental uptake of follow-up services. BMC Public Health 2009;9.

55. Ramesh A, Jagdish C, Nagapoorinima M, et al. Low cost calibrated mechanical noisemaker for hearing screening of neonates in resource constrained settings. Indian J Med Res 2012:135:170-6.

56. Ramkumar V, Hall JW, Nagarajan R, et al. Tele-ABR using a satellite connection in a mobile van for newborn hearing testing. $J$ Telemed Telecare 2013;19:233-7.

57. Ramkumar V, John KR, Selvakumar K, et al. Cost and outcome of a community-based paediatric hearing screening programme in rural India with application of tele-audiology for follow-up diagnostic hearing assessment. Int $J$ Audiol 2018:1-8.

58. Ramkumar V, Vanaja CS, Hall JW, et al. Validation of DPOAE screening conducted by village health workers in a rural community with real-time click evoked tele-auditory brainstem response. Int $J$ Audiol 2018:1-6.

59. Roy E, Hasan KZ, Haque F, et al. Acute otitis media during the first two years of life INA rural community in Bangladesh: a prospective cohort study. J Health Popul Nutr 2007;25:414-21.
60. Sánchez D, Adamovich S, Ingram M, et al. The potential in preparing community health workers to address hearing loss. J Am Acad Audiol 2017;28:562-74.

61. Shrestha R, Baral K, Weir N. Community ear care delivery by community ear assistants and volunteers: a pilot programme. $J$ Laryngol Otol 2001;115:869-73.

62. Smith AC, Armfield NR, Wu W-I, et al. A mobile telemedicineenabled ear screening service for Indigenous children in Queensland: activity and outcomes in the first three years. $J$ Telemed Telecare 2012;18:485-9.

63. Smith AC, Brown C, Bradford N, et al. Monitoring ear health through a telemedicine-supported health screening service in Queensland. J Telemed Telecare 2015;21:427-30.

64. Wagner J, Bonamigo AW, Oliveira Fde, et al. Monitoring of hearing and language in primary health care: project pilot. Cien Saude Colet 2017;22:3599-606.

65. Youngs R, Weir N, Tharu P, et al. Diagnostic otoscopy skills of community ear assistants in Western Nepal. $J$ Laryngol Otol 2011;125:27-9.

66. Jotheeswaran AT, Dias A, Philp I, et al. Identifying common impairments in frail and dependent older people: validation of the cope assessment for non-specialised health workers in low resource primary health care settings. Bmc Geriatrics 2015;15.

67. Pirozzo S, Papinczak T, Glasziou P. Whispered voice test for screening for hearing impairment in adults and children: systematic review. BMJ 2003;327.

68. Mahomed-Asmail F, Swanepoel DW, Eikelboom RH, et al. Clinical validity of hearScreen ${ }^{\mathrm{TM}}$ smartphone hearing screening for school children. Ear Hear 2016;37:e11-17.

69. Daya $\mathrm{H}$, Hinton $\mathrm{AE}$, Radomskiej $\mathrm{P}$, et al. Otoacoustic emissions: assessment of hearing after tympanostomy tube insertion. Clin Otolaryngol Allied Sci 1996;21:492-4.

70. Winton A, Smyth V, Kei J, et al. Infant hearing screening: a comparison of two techniques. Aust N Z J Public Health 1998;22:261-5.

71. Wintermeyer SM, Hart MC, Nahata MC. Efficacy of ototopical ciprofloxacin in pediatric patients with otorrhea. Otolaryngol Head Neck Surg 1997;116:450-3.

72. Nzioki JM, Ouma J, Ombaka JH, et al. Community health worker interventions are key to optimal infant immunization coverage, evidence from a pretest-posttest experiment in Mwingi, Kenya. Pan Afr Med J 2017;28.

73. Bittencourt L, Scarinci IC. Is there a role for community health workers in tobacco cessation programs? Perceptions of administrators and health care professionals. Nicotine Tob Res 2014;16:626-31.

74. Olusanya BO, Neumann KJ, Saunders JE. The global burden of disabling hearing impairment: a call to action. Bull World Health Organ 2014;92:367-73.

75. Scott K, Beckham SW, Gross M, et al. What do we know about community-based health worker programs? A systematic review of existing reviews on community health workers. Hum Resour Health 2018;16.

76. Bazzano AN, Martin J, Hicks E, et al. Human-centred design in global health: a scoping review of applications and contexts. PLOS One 2017;12:e0186744

77. Giacomin J. What is human centred design? Design J 2014;17:606-23.

82. Mullaney T, Pettersson $\mathrm{H}$, Nyholm $\mathrm{T}$, et al. Thinking beyond the cure: a case for human-centered design in cancer care. Int $J$ Design 2012;6.

79. Catalani C, Green E, Owiti P, et al. A clinical decision support system for integrating tuberculosis and HIV care in Kenya: a humancentered design approach. PLoS One 2014:9:e103205.

80. Wilson JMG, Jungner G. Principles and practice of screening for disease. Geneva: Switzerland, 1968.

81. Kok M. Improving the performance of community health workers: what can be learned from the literature? 2018. Available: http://www. chwcentral.org/blog/improving-performance-community-healthworkers-what-can-be-learned-literature

82. Palazuelos D, Farmer PE, Mukherjee J. Community health and equity of outcomes: the partners in Health experience. Lancet Glob Health 2018;6:e491-3.

83. Winters N, O'Donovan J, Geniets A. A new era for community health in countries of low and middle income? Lancet Glob Health 2018;6:e489-90

84. O'Donovan J, O'Donovan C, Kuhn I, et al. Ongoing training of community health workers in low-income and middle-income countries: a systematic scoping review of the literature. BMJ Open 2018;8 
85. O'Donovan J, Bersin A, O'Donovan C. The effectiveness of mobile health (mHealth) technologies to train healthcare professionals in developing countries: a review of the literature. BMJ Innov 2015;1:33-6.

91. Henry JV, Winters N, Lakati A, et al. Enhancing the supervision of community health workers with WhatsApp mobile messaging: qualitative findings from 2 low-resource settings in Kenya. Global Health 2016;4:311-25.
87. Mandavia R, Lapa T, Smith M, et al. A cross-sectional evaluation of the validity of a smartphone otoscopy device in screening for ear disease in Nepal. Clin Otolaryngol 2018;43:31-8.

88. Bright T, Pallawela D. Validated smartphone-based Apps for ear and hearing assessments: a review. JMIR Rehabil Assist Technol 2016;3:e13.

89. Taylor C, Griffiths F, Lilford R. Affordability of comprehensive community health worker programmes in rural sub-Saharan Africa. BMJ Glob Health 2017;2:e000391. 